\title{
Anti-ALK Antibodies in Patients with ALK-Positive Malignancies Not Expressing NPM-ALK
}

\author{
Christine Damm-Welk ${ }^{1 凶}$, Faraz Siddiqi², Matthias Fischer ${ }^{3,4,5}$, Barbara Hero ${ }^{3}$, Vignesh Narayanan ${ }^{6}$, David \\ Ross Camidge, Michael Harris², Amos Burke7, Thomas Lehrnbecher ${ }^{8}$, Karen Pulford ${ }^{9}$, Ilske Oschlies ${ }^{10}$, \\ Reiner Siebert ${ }^{11}$, Suzanne Turner ${ }^{2 *}$ and Wilhelm Woessmann ${ }^{1 * 凶}$ \\ 1. NHL-BFM Study Centre and Department of Paediatric Haematology and Oncology, Justus-Liebig-University, Giessen, Germany \\ 2. Department of Pathology, University of Cambridge, Cambridge UK \\ 3. Department of Paediatric Haematology and Oncology University of Cologne, Germany \\ 4. Centre for Molecular Medicine Cologne, Medical Faculty, University of Cologne, Germany \\ 5. Max Planck Institute for Metabolism Research, Cologne, Germany \\ 6. University of Colorado Cancer Centre, Aurora, Colorado, USA \\ 7. Department of Paediatric Oncology, Addenbrooke's Hospital, Cambridge, UK \\ 8. Department of Paediatric Haematology and Oncology, Goethe University, Frankfurt, Germany \\ 9. Nuffield Division of Clinical Laboratory Sciences, University of Oxford, Oxford, UK \\ 10. Department of Pathology, Christian-Albrechts-University, Kiel, Germany \\ 11. Institute of Human Genetics, Christian-Albrechts-University and University Hospital Schleswig Holstein, Campus Kiel, Kiel Germany \\ * Joint senior authors
}

$\square$ Corresponding authors: Christine Damm-Welk, PhD, or Willi Woessmann, MD, Justus-Liebig-University, Department of Paediatric Haematology and Oncology, Feulgenstr. 12, D-35392 Giessen, Germany. Phone: ++49/641/99-43421; Fax: ++49/641/99-43421; e-mail: Christine.Damm-Welk @paediat.med.uni-giessen.de; Wilhelm.Woessmann@paediat.med.uni-giessen.de

() Ivyspring International Publisher. Reproduction is permitted for personal, noncommercial use, provided that the article is in whole, unmodified, and properly cited. See http://ivyspring.com/terms for terms and conditions.

Received: 2016.02.10; Accepted: 2016.06.01; Published: 2016.06.30

\begin{abstract}
Patients with Nucleophosmin (NPM)- Anaplastic Lymphoma Kinase (ALK) fusion positive Anaplastic Large Cell Lymphoma produce autoantibodies against ALK indicative of an immune response against epitopes of the chimeric fusion protein. We asked whether ALK-expression in other malignancies induces specific antibodies. Antibodies against ALK were detected in sera of one of 50 analysed ALK-expressing neuroblastoma patients, 13 of 21 ALK positive non-small cell lung carcinoma (NSCLC) patients, 13 of 22 ALK translocation-positive, but NPM-ALK-negative lymphoma patients and one of one ALK-positive rhabdomyosarcoma patient, but not in 20 healthy adults. These data suggest that boosting a pre-existent anti-ALK immune response may be more feasible for patients with ALK-positive NSCLC, lymphomas and rhabdomyosarcomas than for tumours expressing wild-type ALK.
\end{abstract}

Key words: ALK-antibody titre, NSCLC, neuroblastoma, lymphoma

\section{Introduction}

The expression of the anaplastic lymphoma kinase (ALK) is silenced after birth with exception of a few scattered neurons in the central nervous system ${ }^{1}$. Almost $90 \%$ of Anaplastic Large Cell Lymphoma (ALCL) in children and adolescents carry a reciprocal translocation $\mathrm{t}(2 ; 5)(\mathrm{p} 23 ; \mathrm{q} 35)$ fusing the Anaplastic Lymphoma Kinase $(A L K)$ gene to Nucleophosmin 1 (NPM1) ${ }^{2-4}$. The resulting NPM-ALK fusion protein is an almost ideal oncoantigen due to its limited distribution in normal tissues and key roles in oncogenic processes ${ }^{1}$. An adaptive immune response to the resulting oncogenic fusion protein has been described in patients with NPM-ALK-positive ALCL $^{5-8}$. Almost all the patients generated autoantibodies specific for the oncoantigen, whereas antibodies could not be detected in healthy adults or children or adults with tumours not expressing ALK $6,8,9$. The magnitude of the antibody response inversely correlates with the risk of relapse ${ }^{8,10}$. Hence, antibody titres might serve as a surrogate for the 
existence and strength of an adaptive B- and/or T-cell response against the aberrant expression of the NPM-ALK protein in ALCL, thereby linking the immune response against NPM-ALK with the ultimate control of NPM-ALK-positive ALCL. As oncogenic rearrangements of ALK or full-length ALK expression have now been described in other cancers, ALK might, serve as an embryonal tumour-associated antigen in all ALK-positive malignancies. Indeed, ALK vaccination has been shown to be effective in preventing disease relapse in a murine tumour model of ALCL and non-small cell lung cancer 7,11.

The existence of an anti-ALK autoantibody response in other cancers associated with aberrant ALK expression might also implicate the use of ALK-directed immunotherapeutic strategies for these diseases. For example, about $10 \%$ of childhood ALK-positive ALCL and the majority of ALK-positive Diffuse Large B Cell Lymphomas (DLBCL) express ALK-fusion proteins with variant fusion partners (X-ALK) besides NPM12,3,12. As the contribution of the NPM1 portion of the fusion protein to the induction of the immune response is not known, it remains to be investigated whether X-ALK fusion proteins likewise initiate an immune response.

Aberrant ALK expression also characterises other malignancies. ALK rearrangements occurs in 3-7\% of Non-Small Cell Lung Cancer (NSCLC) patients, where an intrachromosomal inversion involving the $A L K$ gene locus (inv(2)(p21p23)) and the echinoderm microtubule associated protein 4 (EML4) gene represents the most common rearrangement detected $^{13}$. ALK positive NSCLC is associated with a younger age at diagnosis, a non-smoking history and the absence of EGFR mutations ${ }^{14,15}$. Cellular expression of EML4-ALK protein is lower than that usually observed in ALK-expressing ALCL rendering it difficult to detect by immunohistochemistry (IHC) with the ALK1 monoclonal antibody15. Overexpression of full length $A L K$ by amplification has been described in $80 \%$ of alveolar rhabdomyosarcomas (RMS) and $20 \%$ of embryonal RMS. ALK expression is driven by amplification of the $A L K$ gene and by increased transcription induced by the tumour-specific PAX3-FOXO1 transcription factor binding to the third intron of the gene ${ }^{16,17}$. The majority of neuroblastomas, the most common extracranial solid tumour in children, express full length $A L K^{18,19}$. The strength of ALK-expression differs and is influenced by $A L K$-amplifications or modified by $A L K$-mutations ${ }^{20}$.

In order to investigate whether ALK-expression in human tumours generally induces an immune response, we analysed the presence of circulating ALK-specific antibodies in patients with
ALK-positive, NPM-ALK negative ALCL, DLBCL, NSCLC, neuroblastoma and RMS as well as further 20 healthy volunteers.

\section{Patients and Methods}

\section{Study population}

Lymphoma cases were selected from patients registered on the ethically approved trials NHL-BFM95 or ALCL99 in Germany between 1995 and 2010 with a diagnosis of ALK-positive ALCL or ALK-positive DLBCL by national reference histology. The patients/parents had given their informed consent to use the material. Selection of cases was based on the presence of ALK-staining restricted to the cytoplasm, the molecularly confirmed absence of NPM-ALK fusion and the availability of serum or plasma samples taken at diagnosis. The DLBCL cases were shown to express Clathrin (CLTC)-ALK by Clathrin-ALK specific RT-PCR ${ }^{2}$. Comparison of the immunohistochemical ALK staining pattern with molecular analyses revealed complete concordance with our previous study2; NPM-ALK positive ALCL expressed ALK in the nucleus as well as the cytoplasm while variant ALK fusion proteins lacked nuclear ALK-staining.

Neuroblastoma patients were selected from a German cohort enrolled onto and treated according to the ethically approved NB97 and NB 2004 trials with informed consent. Patients with ALK-expressing tumours detected by real-time PCR and available serum samples during the first four weeks after initial tumour biopsy were included in this study. Mutations were analysed by sequencing.

NSCLC patients $(n=21 ; 7$ female, 14 male; age range 33-83, median age 59; 14 never smokers) were treated at the Colorado Cancer Center. All NSCLC patients had stage IV disease at the time of blood sampling and were proven ALK-rearrangement positive by FISH as previously described ${ }^{21}$. Two patients were on no treatment at the time of sampling, all others were receiving treatment with either a licensed or experimental ALK inhibitor (Crizotinib, $\mathrm{n}=12$; LDK378, $\mathrm{n}=4 ; \mathrm{AP} 26113, \mathrm{n}=2$ ) or pemetrexed $(\mathrm{n}=1)$.

The patient with ALK-positive alveolar rhabdomyosarcoma stage IV showed ALK-staining by IHC and was included after informed consent for measuring ALK antibodies had been secured.

20 healthy adults were included as control group in a study about the characterisation of the cellular and humoral ALK-immune response approved by the ethical committee of the corresponding authors (number: 193/11) after written informed consent. 


\section{Detection of the antibody response against ALK}

Cytocentrifuge preparations of COS-1 cells (DSMZ, Braunschweig, Germany) transiently transfected with $p c D N A_{3}$ expression plasmids harbouring the entire coding sequences of NPM-ALK, Tropomyosin 3 (TPM3)-ALK, EML4-ALK, full length $A L K$ or $p c D N A_{3}$ vector only were prepared and incubated with patient's serum diluted $1 / 50$ and $1 / 100$. Patients with a positive staining result were further analysed using serial 3 fold dilution of the serum from $1 / 250$ to $1 / 60750$ as previously described $^{8}$. Antigen-antibody complexes were visualised by indirect immunoperoxidase staining using HRP-rabbit anti-human IgG antibody and diaminobezidine-tetrahydrochloride. The cut-off for a positive result was taken as the highest dilution before the staining of the ALK transfectants was no longer visible by two independent observers 5 . Cos- 1 cells transfected with $\mathrm{pcDNA}_{3}$ vector only were used to control for background as well as false positive staining.

\section{Results and Discussion}

We studied 94 patients with ALK-positive, NPM-ALK negative malignancies and 20 healthy control persons for the presence of anti-ALK titres as a surrogate for the existence and strength of the immune response against ALK. The range of malignancies examined included Lymphoma (ALCL and DLBCL), neuroblastoma, NSCLC and one case of rhabdomyosarcoma.

ALK-positive lymphoma was diagnosed in 22 children/adolescents at a median age of 12.4 years (range 2.3-18.2 years). All tumours had ALK translocations but were NPM-ALK fusion negative. Of the 20 patients diagnosed with X-ALK positive ALCL $12(60 \%)$ mounted a specific antibody response against ALK with titres ranging from $1 / 250$ to $1 / 60750$ (median 1/750; Table 1). This is a lower incidence than previously reported for patients with NPM-ALK-positive ALCL of whom $90 \%$ produce ALK-antibodies although it must be considered that the numbers of patients assessed in this study is considerably lower 8,9 . ALK-specific antibodies were detected in one of the two patients with CLTC-ALK positive DLBCL (titre: $1 / 6750$ ).

In contrast, only one of the 50 children (median age 1.3 years, range 0.1-13.3) with ALK-expressing neuroblastoma (including four cases with MYC-N amplification and 11 with chromosome $1 \mathrm{p}$-abnormalities) had a detectable antibody titre, and even this response was weak $(1 / 100)$. This patient had stage 4 disease; the tumour didn't show MYC-N amplification or $1 \mathrm{p}$ deletion or somatic $A L K$ mutations. The characteristics of ALK-expression in neuroblastoma differ in many aspects from those of lymphoma patients, which may account for the missing immune response: Transmembrane full-length ALK or variants with point mutations are expressed in neuroblastoma and ALK is usually expressed at far lower levels in neuroblastoma than are detected in ALCL. In addition to the differences in ALK-expression in neuroblastoma, the generation of ALK antibodies in patients with ALK-positive cancer likely also involves other factors. These include the levels of expression of the oncoprotein itself but also other tumour characteristics and the tumour microenvironment. For example, it has been reported that neuroblastoma cells can dampen the immune response by down-regulating expression of HLA 22,23 . Furthermore, they release soluble inhibitors of the immune system, e.g. gangliosides 24. Additionally, since neuroblastomas often arise prenatally further tolerance mechanisms may be active.

Table 1: Anti-ALK antibody titres in patients with ALK positive malignancies other than NPM-ALK-positive ALCL

\begin{tabular}{|c|c|c|c|c|c|}
\hline & ALCL & DLBCL & RMS & NBL & NSCLC \\
\hline $\mathrm{N}$ & 20 & 2 & 1 & 50 & 21 \\
\hline \multicolumn{6}{|l|}{ ALK aberration } \\
\hline Translocation/inversion & 20 & 2 & - & - & 21 \\
\hline Amplification & - & - & 1 & - & - \\
\hline Point mutation & - & - & - & 6 & - \\
\hline No specific aberration & - & - & - & 44 & - \\
\hline \multicolumn{6}{|l|}{ Anti-ALK titre } \\
\hline 0 & 8 & 1 & 0 & 49 & 8 \\
\hline$\leq 1 / 750$ & 3 & 0 & 1 & 1 & 10 \\
\hline $1 / 2250-1 / 20250$ & 5 & 1 & 0 & 0 & 2 \\
\hline$\geq 1 / 60750$ & 4 & 0 & 0 & 0 & 1 \\
\hline \multicolumn{6}{|l|}{ Stage* } \\
\hline 1 & 1 & 0 & 0 & 18 & 0 \\
\hline 2 & 5 & 2 & 0 & 8 & 0 \\
\hline 3 & 10 & 0 & 0 & 7 & 0 \\
\hline 4 & 3 & 0 & 1 & 12 & 21 \\
\hline $4 S$ & $\mathrm{~N} / \mathrm{A}$ & $\mathrm{N} / \mathrm{A}$ & $\mathrm{N} / \mathrm{A}$ & 5 & $\mathrm{~N} / \mathrm{A}$ \\
\hline $\begin{array}{l}\text { Not known } \\
\text { outcome }\end{array}$ & 1 & - & - & - & - \\
\hline CCR & 15 & 1 & 0 & 32 & 1 \\
\hline Relapse/alive & 5 & 0 & 0 & 6 & $11^{\mathrm{a}}$ \\
\hline Relapse/DOD & 0 & 1 & 1 & 12 & $6^{b}$ \\
\hline Unknown & & & & & 3 \\
\hline
\end{tabular}

In contrast to the patients with ALK-positive neuroblastoma, the 19 year old patient with alveolar RMS and high expression of full-length ALK clearly produced ALK antibodies. Even though only one RMS patient was assessed this suggests that expression of full length ALK does not preclude the immune response and that anti-ALK immunity 
should be systematically analysed in ALK-positive RMS.

The majority of ALK expressing NSCLC patients had progressive disease and 19 of the 21 had undergone prior chemotherapy, in some cases multiple rounds. Prior therapies and long-standing disease might have suppressed the immune response or, at least, lowered the antibody titre as has been observed in ALCL-patients ${ }^{9}$. Therefore, the strength of the immune response might not reflect the titres at initial diagnosis. Despite this limitation, 10 of the 21 ALK-positive NSCLC patients mounted a weak antibody response against ALK $(\leq 1 / 750)$ with eight having no titre at all, two patients displaying moderate titres $(>750-<60750)$ and one patient having a high titre $(\geq 1 / 60750)$ (Table 1$)$. In addition to the influence of prior therapy on the antibody response, NSCLC, like neuroblastoma, express lower cellular levels of aberrant ALK in comparison to lymphomas ${ }^{21}$. Furthermore, as in neuroblastoma, HLA-down-regulation has been described in NSCLC $^{25}$. However, these data do indicate that an ALK-specific immune response exists in NSCLC-patients. Our results raise the possibility of boosting the ALK-directed immune response as a therapeutic strategy in patients with ALK-positive NSCLC which is of special interest in light of the still dismal prognosis even with ALK-inhibitor therapy. Furthermore, these data suggest that further studies of ALK antibody titre in NSCLC are warranted, in particular of patients at first disease presentation.

The sera of X-ALK-positive ALCL-patients in this study reacted against NPM-ALK, TPM3-ALK and full-length-ALK transfected COS cells and sera from patients with NPM-ALK- positive ALCL stained cells expressing theTPM3-ALK fusion protein (Supplementary Figure S1). Likewise, sera from ALK-positive NSCLC patients stained both EML4-ALK and NPM-ALK transfectants (data not shown). These data suggest that the auto-antibodies target the ALK-portion of the fusion proteins indicating that the immune response is directed against the embryonal ALK tumour-associated antigen rather than an epitope from the tumour-specific X-ALK fusion site.

None of the 20 healthy control persons had detectable anti-ALK antibodies in their serum. Together with our previous data this equates to more than 100 adults without ALK-expressing tumours (50 healthy at the time of analysis) who do not have a detectable humoral immune response against ALK. These data suggest that unspecific autoimmune reactions against ALK are rare in the absence of ALK-expressing tumours.

In summary, antibody responses against ALK fusion proteins are not restricted to NPM-ALK-positive ALCL but can be detected in most patients with variant ALK-fusion partners in both ALCL and DLBCL, as well as in one ALK-positive RMS and half of the patients with ALK-positive NSCLC in contrast to the vast majority of patients with ALK-positive neuroblastoma. Our data suggests that inter-individual differences in immune response modifiers may not be the sole determinant as to whether a patient elicits an immune response against ALK. Dependent on the strength and kind of ALK expression (full-length versus fusion protein), tumour cell type and age at tumour development, different immune escape mechanisms may be active. Boosting a pre-existent anti-ALK immune response may be more feasible for patients with ALK-positive NSCLC, lymphomas and rhabdomyosarcomas than for tumours expressing wild-type ALK.

\section{Supplementary Material}

Supplementary Figure S1.

http://www.jcancer.org/v07p1383s1.pdf

\section{Abbreviations}

ALK: anaplastic lymphoma kinase; ALCL: Anaplastic Large Cell Lymphoma; CLTC: clathrin; DLBCL: Diffuse Large B Cell Lymphoma; EML4: echinoderm microtubule associated protein like-4; IHC: immunohistochemistry; NHL: Non-Hodgkin Lymphoma; NPM1: nucleophosmin 1; NSCLC: non-small cell lung carcinoma; RMS: rhabdomyosarcoma; TPM3: Tropomyosin 3; X-ALK: ALK fusion proteins with variant fusion partners.

\section{Acknowledgements}

The authors would like to thank the staff of the NHL-BFM laboratory for expert technical assistance.

\section{Funding}

This work was supported by a grant from the Deutsche Jose Carreras Leukämie-Stiftung (DJCLS08/ 09) to WW, and RS. CDW and WW are additionally supported by the von behring röntgen stiftung (60-0011) and the Forschungshilfe Peiper, IO and RS by the Kinderkrebsinitiative Buchholz/HolmSeppensen and KP by Bloodwise, the Julian Starmer-Smith Memorial Fund and the Sam Foye Fund. SDT is a Bloodwise University Senior Lecturer and is also supported by the Alex Hulme Foundation and the Sam Foye Fund. MH is supported by a PhD studentship from the Wellcome Trust.

\section{Authorship}

CDW and WW designed and coordinated the study. FS, MH, SDT, KP and CDW measured 
antibody titres and performed molecular analyses. MF, TL, RC, VN, CDW and WW collected samples and provided clinical data. These data were analysed by CDW, SDT, AB and WW. IO performed in depth histological evaluations and collected samples. RS performed and evaluated molecular cytogenetic analysis. CDW, SDT and WW wrote the paper. All authors approved the final version of the manuscript.

\section{Competing Interests}

The authors have declared that no competing interest exists.

\section{References}

1. Pulford K, Lamant L, Espinos E, Jiang Q, Xue L, Turturro F, Delsol G, Morris SW. The emerging normal and disease-related roles of anaplastic lymphoma kinase. Cell Mol.Life Sci. 2004;61:2939-53.

2. Damm-Welk C, Klapper W, Oschlies I, Gesk S, Rottgers S, Bradtke J, Siebert R, Reiter A, Woessmann W. Distribution of NPM1-ALK and X-ALK fusion transcripts in paediatric anaplastic large cell lymphoma: a molecular-histological correlation. Br.J.Haematol. 2009;146:306-09.

3. Perkins SL, Pickering D, Lowe EJ, Zwick D, Abromowitch M, Davenport G, Cairo MS, Sanger WG. Childhood anaplastic large cell lymphoma has a high incidence of ALK gene rearrangement as determined by immunohistochemical staining and fluorescent in situ hybridisation: a genetic and pathological correlation. Br.J.Haematol. 2005;131:624-27.

4. Lamant L, McCarthy K, D'Amore E, Klapper W, Nakagawa A, Fraga M, Maldyk J, Simonitsch-Klupp I, Oschlies I, Delsol G, Mauguen A, Brugieres L, et al. Prognostic Impact of Morphologic and Phenotypic Features of Childhood ALK-Positive Anaplastic Large-Cell Lymphoma: Results of the ALCL99 Study. J.Clin.Oncol. 2011;29:4669-76.

5. Pulford K, Falini B, Banham AH, Codrington D, Roberton H, Hatton C, Mason DY. Immune response to the ALK oncogenic tyrosine kinase in patients with anaplastic large-cell lymphoma. Blood 2000;96:1605-07.

6. Ait-Tahar K, Cerundolo V, Banham AH, Hatton C, Blanchard T, Kusec R, Becker M, Smith GL, Pulford K. B and CTL responses to the ALK protein in patients with ALK-positive ALCL. Int.J.Cancer 2006;118:688-95.

7. Chiarle R, Martinengo C, Mastini C, Ambrogio C, D'Escamard V, Forni G, Inghirami G. The anaplastic lymphoma kinase is an effective oncoantigen for lymphoma vaccination. Nat.Med. 2008;14:676-80.

8. Ait-Tahar K, Damm-Welk C, Burkhardt B, Zimmermann M, Klapper W, Reiter A, Pulford K, Woessmann W. Correlation of the autoantibody response to the ALK oncoantigen in pediatric anaplastic lymphoma kinase-positive anaplastic large cell lymphoma with tumor dissemination and relapse risk. Blood 2010;115:3314-19.

9. Mussolin L, Bonvini P, Ait-Tahar K, Pillon M, Tridello G, Buffardi S, Lombardi A, Pulford K, Rosolen A. Kinetics of humoral response to ALK and its relationship with minimal residual disease in pediatric ALCL. Leukemia 2009;23:400-2.

10. Mussolin L, Damm-Welk C, Pillon M, Zimmermann M, Franceschetto G, Pulford K, Reiter A, Rosolen A, Woessmann W. Use of minimal disseminated disease and immunity to NPM-ALK antigen to stratify ALK-positive ALCL patients with different prognosis. Leukemia 2013;27:416-22.

11. Voena C, Menotti M, Mastini C, Di Giacomo F, Longo DL, Castella B, Merlo ME, Ambrogio C, Wang Q, Minero VG, Poggio T, Martinengo C, et al. Efficacy of a Cancer Vaccine against ALK-Rearranged Lung Tumors. Cancer immunology research 2015;3:1333-43.

12. Gascoyne RD, Lamant L, Martin-Subero JI, Lestou VS, Harris NL Muller-Hermelink HK, Seymour JF, Campbell LJ, Horsman DE, Auvigne I, Espinos E, Siebert R, et al. ALK-positive diffuse large B-cell lymphoma is associated with Clathrin-ALK rearrangements: report of 6 cases. Blood 2003:102:2568-73.

13. Soda M, Choi YL, Enomoto M, Takada S, Yamashita Y, Ishikawa S, Fujiwara S, Watanabe H, Kurashina K, Hatanaka H, Bando M, Ohno S, et al. Identification of the transforming EML4-ALK fusion gene in non-small-cell lung cancer. Nature 2007;448:561-6.

14. Shaw AT, Yeap BY, Mino-Kenudson M, Digumarthy SR, Costa DB, Heist RS, Solomon B, Stubbs H, Admane S, McDermott U, Settleman J, Kobayashi S, et al. Clinical features and outcome of patients with non-small-cell lung cancer who harbor EML4-ALK. Journal of clinical oncology : official journal of the American Society of Clinical Oncology 2009;27:4247-53.

15. Rodig SJ, Mino-Kenudson M, Dacic S, Yeap BY, Shaw A, Barletta JA, Stubbs H, Law K, Lindeman N, Mark E, Janne PA, Lynch T, et al. Unique clinicopathologic features characterize ALK-rearranged lung adenocarcinoma in the western population. Clinical cancer research : an official journal of the American Association for Cancer Research 2009;15:5216-23.
16. Cao $\mathrm{L}, \mathrm{Yu} \mathrm{Y}$, Bilke $\mathrm{S}$, Walker RL, Mayeenuddin LH, Azorsa DO, Yang $\mathrm{F}$, Pineda M, Helman LJ, Meltzer PS. Genome-wide identification of PAX3-FKHR binding sites in rhabdomyosarcoma reveals candidate target genes important for development and cancer. Cancer research 2010;70:6497-508.

17. van Gaal JC, Flucke UE, Roeffen $\mathrm{MH}$, de Bont ES, Sleijfer S, Mavinkurve-Groothuis AM, Suurmeijer AJ, van der Graaf WT, Versleijen-Jonkers YM. Anaplastic lymphoma kinase aberrations in rhabdomyosarcoma: clinical and prognostic implications. Journal of clinical oncology : official journal of the American Society of Clinical Oncology 2012;30:308-15.

18. Lamant L, Pulford K, Bischof D, Morris SW, Mason DY, Delsol G, Mariamé B. Expression of the ALK Tyrosine Kinase Gene in Neuroblastoma. The American Journal of Pathology 2000;156:1711-21.

19. Osajima-Hakomori Y, Miyake I, Ohira M, Nakagawara A, Nakagawa A, Sakai R. Biological Role of Anaplastic Lymphoma Kinase in Neuroblastoma. The American Journal of Pathology 2005;167:213-22.

20. Schulte JH, Bachmann HS, Brockmeyer B, Depreter $\mathrm{K}$, Oberthur A, Ackermann S, Kahlert Y, Pajtler K, Theissen J, Westermann F, Vandesompele J, Speleman F, et al. High ALK receptor tyrosine kinase expression supersedes ALK mutation as a determining factor of an unfavorable phenotype in primary neuroblastoma. Clinical cancer research : an official journal of the American Association for Cancer Research 2011;17:5082-92.

21. Camidge DR, Kono SA, Flacco A, Tan AC, Doebele RC, Zhou Q, Crino L, Franklin WA, Varella-Garcia M. Optimizing the detection of lung cancer patients harboring anaplastic lymphoma kinase (ALK) gene rearrangements potentially suitable for ALK inhibitor treatment. Clinical cancer research : an official journal of the American Association for Cancer Research 2010;16:5581-90.

22. Cheung NK, Dyer MA. Neuroblastoma: developmental biology, cancer genomics and immunotherapy. Nature reviews. Cancer 2013;13:397-411.

23. Raffaghello L, Prigione I, Airoldi I, Camoriano M, Morandi F, Bocca P, Gambini C, Ferrone S, Pistoia V. Mechanisms of immune evasion of human neuroblastoma. Cancer letters 2005;228:155-61.

24. Schulz G, Cheresh DA, Varki NM, Yu A, Staffileno LK, Reisfeld RA. Detection of ganglioside GD2 in tumor tissues and sera of neuroblastoma patients. Cancer research 1984;44:5914-20.

25. Korkolopoulou P, Kaklamanis L, Pezzella F, Harris AL, Gatter KC. Loss of antigen-presenting molecules (MHC class I and TAP-1) in lung cancer. British journal of cancer 1996;73:148-53. 